Pulse

\section{International aid doldrums}

$\mathrm{O}$ f late, the promises have been plentiful but the hard numbers indicate the gap between Canadian outlays for foreign aid and the $0.7 \%$ of GNP target, first urged by ex-Prime Minister and Nobel Laureate Lester Pearson in the late ig6os, remains substantial (see related article on page 7I).

Although the $0.7 \%$ target is now the UN benchmark for foreign aid expected of developed nations, statistics suggest Canada will continue to receive failing grades for the foreseeable future, even if Prime Minister Stephen Harper honours his January 2006 election commitment to hike international aid by $\$ 425$ million over 5 years and move Canada toward the average foreign aid outlay of Organisation for Economic Co-operation and Development (OECD) member nations roughly $0.42 \%$ of gross national income.

Reaching the OECD target will require additional outlays of several orders of magnitude higher the $\$ 425$ million promised by Harper, which, rather notably, was absent in the Conservative government's first budget last March.

His vow, though, would help to redress the harsh reality that Canada's \$2719-billion outlay in 2003/04 (a decline of $\$ 583$ million over the previous year) constituted a 38 -year low as a percentage of GNP, coming in at $0.23 \%$. Not since 1965 , when it was $0.22 \%$ of GNP, had Canadian aid fallen so low.

The numbers began to rebound in 2005, when the predecessor Liberal government's last budget increased foreign aid to $\$ 3237.2$ billion and locked-in annual $8 \%$ increases through 20I0. The 2005 hike included health-related items such as \$10o million for WHO's " 3 by 5" initiative; $\$ 70$ million for the Global Fund to Fight HIV/AIDS, Tuberculosis and Malaria; \$15 million for the International Partnerships for Microbicides; and $\$ \mathrm{I} 60$ million for the Global Alliance for Vaccines and Immunization.

The automatic $8 \%$ increase hiked overall aid spending to a projected $\$ 3637$ billion in the 2005/06 fiscal year. When similar increases are factored in through 2010, Canada's foreign aid

Table 1: Health-related disbursements

\begin{tabular}{|c|c|c|}
\hline \multirow[b]{2}{*}{ Recipient } & \multicolumn{2}{|c|}{ Disbursement, \$ millions } \\
\hline & $2001 / 02$ & $2003 / 04$ \\
\hline \multicolumn{3}{|l|}{ International organization } \\
\hline World Health Organization & - & 4.0 \\
\hline WHO Tropical Diseases Research Program & 1.4 & - \\
\hline WHO Canadian International Immunization Initiative & 9.6 & 6.4 \\
\hline WHO Global Polio Eradication Initiative & - & 10.4 \\
\hline UN Programme on HIV/AIDS & 3.5 & 5.0 \\
\hline UNICEF & - & 1.0 \\
\hline UNICEF Canadian International Immunization Initiative & 9.2 & 6.4 \\
\hline UNICEF Global Alliance on Vaccines and Immunization & 3.0 & 6.0 \\
\hline UNICEF Global Polio Eradication Initiative & - & 2.6 \\
\hline \multicolumn{3}{|l|}{ International humanitarian assistance (multilateral) } \\
\hline International Committee of the Red Cross & - & 9.0 \\
\hline \multicolumn{3}{|l|}{ Program against hunger, malnutrition and disease } \\
\hline World Food Program & 19.9 & 72.0 \\
\hline WHO & 12.3 & - \\
\hline UNICEF & 28.4 & 10.5 \\
\hline Global Fund to fight AIDS, TB and Malaria & 80.0 & 25.2 \\
\hline Global TB Drug Facility - WBTF & - & 15.0 \\
\hline Micronutrient Initiative & 28.3 & 28.0 \\
\hline $\begin{array}{l}\text { International Union against TB \& Lung Disease - DOTS } \\
\text { expansion }\end{array}$ & 2.8 & 10.1 \\
\hline
\end{tabular}

Note: WBTF $=$ World Bank Trust Fund, DOTS = Directly Observed Therapy Shortcourse

outlay will rebound to about $0.36 \%$ of GNP.

Neither the Department of Foreign Affairs nor the Canadian International Development Agency say they're able to provide a line-item breakdown of aid outlays for the past 2 fiscal years because specific allocations remain in flux. Outlays are made in either fiscal or calendar years and it usually takes a few years before the final totals are known for a fiscal year, explains CIDA spokesperson Bronwyn Cruden.

According to the most recent specific figures (fiscal 2003/04), roughly $\$$ Ir8 million was spent on health or health-related aid, ranging from medical services to policy advice (see Table I for highlights). However, CIDA projected in its annual priorities and planning submission to Parliament that health-related spending would increase to $\$ 452$ million in 2004/05 and to $\$ 619.3$ million in 2005/06.

Some $\$$ I.272 billion of the $\$ 3637$ billion international aid budget for
2005/06 is ticketed for so-called "geographic" programs in Africa, the Middle East, the Americas and Asia. The budget also allocated roughly \$8II million for multilateral programs, including \$34I.2 million for programming against hunger, malnutrition and disease, \$9I million for international humanitarian assistance, $\$ 183.2$ million for international financial institutions, and \$195.8 million for United Nations and Commonwealth programs. As well, \$266 million was issued for partnership programs, \$12.5 million for "policy coherence," \$20 million for "Engaging Canadians" (including \$ro-million for Canada Corps), ands \$2I4.9 million for administration. The remaining \$989.9 million of the aid budget was ticketed for spending by other departments, such as Finance, National Defence and Foreign Affairs, for things such as debt relief or international peace and security initiatives. - Wayne Kondro, CMAJ

DOI:Io.I503/cmaj.06I597 